\title{
Effect of sintering condition on the microstructure and electrical properties of lead-free $\left(\mathrm{Na}_{0.5} \mathrm{~K}_{0.5}\right) \mathrm{NbO}_{3}$ - $\mathrm{Bi}_{0.5}\left(\mathrm{Na}_{0.83} \mathrm{~K}_{0.17}\right)_{0.5} \mathrm{TiO}_{3}$ ceramics
}

\author{
Chun Huy Wang ${ }^{1,2, a}$ \\ ${ }^{1}$ Department of Electronic Engineering, Nan-Jeon University, Tainan City 737, Taiwan \\ ${ }^{2}$ Graduate School of Engineering Science and Technology, Nan-Jeon University, Tainan City 737, Taiwan
}

\begin{abstract}
In this work, the piezoelectric ceramic system of the $(1-\mathrm{x})\left(\mathrm{Na}_{0.5} \mathrm{~K}_{0.5}\right) \mathrm{NbO}_{3}$ $x B i\left(N_{0.83} \mathrm{~K}_{0.17}\right) \mathrm{TiO}_{3}$ with composition close to the morphotropic phase boundary is studied. $\left(\mathrm{Na}_{0.5} \mathrm{~K}_{0.5}\right) \mathrm{NbO}_{3}$ with $0 \sim 5$ mole\% $\mathrm{Bi}\left(\mathrm{Na}_{0.83} \mathrm{~K}_{0.17}\right) \mathrm{TiO}_{3}$ has been prepared following the conventional mixed oxide process. The effect of sintering time on the properties of $0.97\left(\mathrm{Na}_{0.5} \mathrm{~K}_{0.5}\right) \mathrm{NbO}_{3}-0.03 \mathrm{Bi}\left(\mathrm{Na}_{0.83} \mathrm{~K}_{0.17}\right) \mathrm{TiO}_{3}$ ceramics is discussed. For $0.97\left(\mathrm{Na}_{0.5} \mathrm{~K}_{0.5}\right) \mathrm{NbO}_{3^{-}}$ $0.03 \mathrm{Bi}\left(\mathrm{Na}_{0.83} \mathrm{~K}_{0.17}\right) \mathrm{TiO} 3$ ceramics, the electromechanical coupling coefficients of the thickness mode kt and the piezoelectric constant $\mathrm{d}_{33}$ reach 0.46 and $155 \mathrm{p} / \mathrm{CN}$, respectively, at the sintering of $1100 \mathrm{oC}$ for $3 \mathrm{~h}$. Dielectric and piezoelectric properties have maximum values at the sintering temperature of $1100{ }^{\circ} \mathrm{C}$ for $5 \mathrm{~h}$. For $0.97\left(\mathrm{Na}_{0.5} \mathrm{~K}_{0.5}\right) \mathrm{NbO}_{3}-0.03 \mathrm{Bi}\left(\mathrm{Na}_{0.83} \mathrm{~K}_{0.17}\right) \mathrm{TiO}_{3}$ ceramics, the electromechanical coupling coefficients of the thickness mode $\mathrm{k}_{\mathrm{t}}$ and the piezoelectric constant $\mathrm{d}_{33}$ reach 0.56 and 190 , respectively, at the sintering of $1100{ }^{\circ} \mathrm{C}$ for $5 \mathrm{~h}$. The effect of prolonging the sintering time to the $0.97\left(\mathrm{Na}_{0.5} \mathrm{~K}_{0.5}\right) \mathrm{NbO}_{3}-0.03 \mathrm{Bi}\left(\mathrm{Na}_{0.83} \mathrm{~K}_{0.17}\right) \mathrm{TiO}_{3}$ system is a helpful method on ceramic processing to improve densification and properties.
\end{abstract}

\section{Introduction}

Lead-free piezoelectric materials, such as langasite single crystal, ferroelectric ceramics with perovskite structure, and Bi-layered structure oxides, have been reported [1-2]. Among these materials, $\left(\mathrm{Na}_{0.5} \mathrm{~K}_{0.5}\right) \mathrm{NbO}_{3}$ [abbreviated as $\mathrm{NKN}$ ] ceramics are considered good candidates for lead-free piezoelectric ceramics because of their strong piezoelectricity and ferroelectricity. The hot-pressed NKN ceramics ( $99 \%$ of theoretical density) have been reported to possess a large piezoelectric longitudinal response $\left(\mathrm{d}_{33} \sim 160 \mathrm{pC} / \mathrm{N}\right)$, a high planar coupling coefficient $\left(k_{\mathrm{p}} \sim 45 \%\right)$, and a high phase transition temperature $\left(T_{\mathrm{c}}=420{ }^{\circ} \mathrm{C}\right)[1]$. NKN ceramics sintered by ordinary sintering show relatively lower values $\left(k_{\mathrm{p}}=25 \%\right)$ due to difficulty in the processing of dense ceramics by ordinary sintering [2]. This issue has received significant attention and has been thoroughly investigated [3-5].

Nevertheless, dense NKN ceramics are difficult to obtain since their phase stability is limited to $1140{ }^{\circ} \mathrm{C}$, which is close to the melting point [6]. Many researchers used hot pressing or spark plasma sintering [abbreviated as SPS] techniques to yield better quality ceramics [7]. The addition of some perovskite compounds to form solid solutions with NKN or synthesis by spark plasma sintering (SPS) has been carried out to obtain lead-free materials suitable for industrial applications. Perovskite

\footnotetext{
${ }^{\mathrm{a}}$ Corresponding author : wangch@ mail.nju.edu.tw
} 
structure $\left(\mathrm{Bi}_{0.5} \mathrm{Na}_{0.5}\right) \mathrm{TiO}_{3}$ [abbreviated as $\mathrm{BNT}$ ] ceramics are considered as one of the candidates for lead-free piezoelectric ceramics because of its high ferroelectric properties and high Curie temperature $\left(\mathrm{T}_{\mathrm{c}}=320^{\circ} \mathrm{C}\right)$. Some modifications of BNT ceramics have proved to be helpful by forming solid solution with other perovskite oxides. $\mathrm{Bi}_{0.5}\left(\mathrm{Na}_{0.83} \mathrm{~K}_{0.17}\right)_{0.5} \mathrm{TiO}_{3}$ is well-known lead-free piezoelectric materials, which has a tetragonal symmetry at room temperature and show better piezoelectric response. However, there have been few studies on the properties of NKN ceramics modified with $\mathrm{Bi}_{0.5}\left(\mathrm{Na}_{0.83} \mathrm{~K}_{0.17}\right)_{0.5} \mathrm{TiO}_{3}$ [abbreviated as $\mathrm{BNKT}$ ]. Therefore, it is desirable to expect that the solid mixture of $\mathrm{NKN}$ (orthorhomic) and $\mathrm{Bi}_{0.5}\left(\mathrm{Na}_{0.83} \mathrm{~K}_{0.17}\right)_{0.5} \mathrm{TiO}_{3}$ (tetragonal) have a morphotropic phase boundary (abbreviated as MPB) and better piezoelectric property. However, there have been few studies on the properties of NKN ceramics modified with $\mathrm{Bi}_{0.5}\left(\mathrm{Na}_{0.83} \mathrm{~K}_{0.17}\right)_{0.5} \mathrm{TiO}_{3}$ [abbreviated as BNKT]. The aim of this study is not only to investigate the physical and electrical properties of the $\left(\mathrm{Na}_{0.5} \mathrm{~K}_{0.5}\right) \mathrm{NbO}_{3}-\mathrm{Bi}_{0.5}\left(\mathrm{Na}_{0.83} \mathrm{~K}_{0.17}\right)_{0.5} \mathrm{TiO}_{3}$ [NKN-BNKT] system by the conventional mixed oxide method, but also to discuss the effect of sintering condition on the microstructure and electrical properties of NKN-BNKT ceramics

\section{Methods and procedures}

The $(1-\mathrm{x})\left(\mathrm{Na}_{0.5} \mathrm{~K}_{0.5}\right) \mathrm{NbO}_{3}-\mathrm{xBi}_{0.5}\left(\mathrm{Na}_{0.83} \mathrm{~K}_{0.17}\right)_{0.5} \mathrm{TiO}_{3} \quad[(1-\mathrm{x}) \mathrm{NKN}-\mathrm{xBNKT}] \quad(\mathrm{x}=0.01,0.02,0.03,0.04$, and 0.05$)$ ceramics were prepared by conventional mixed oxide method. The powders were calcined at $950{ }^{\circ} \mathrm{C}$ for $4 \mathrm{~h}$. The disc samples were sintered in alumina crucible at $1100{ }^{\circ} \mathrm{C}$ for $3 \sim 7 \mathrm{~h}$ in air atmosphere. To measure relevant piezoelectric properties, the prepared ceramic samples were polarized in silicone oil at $160{ }^{\circ} \mathrm{C}$ under $4 \mathrm{kV} / \mathrm{mm}$ for $30 \mathrm{~min}$. An X-ray diffractometer (Seimens D5000) using $\mathrm{Cu} \mathrm{K} \alpha$ radiation was used to evaluate the crystal structure of the sintered ceramics. The room temperature dielectric constant at $1 \mathrm{kHz}$ was measured by LCR meter. The piezoelectric properties were measured by a resonance-antiresonance method based on IEEE standards using an impedance/gain-phase analyzer (Angilent 4194). Samples for observations of the microstructure were polished and thermally etched. The microstructures were observed by a scanning electron microscope (SEM). The mean grain size was calculated by the line intercept method. The density was measured by Archimedes method.

\section{Results and discussion}

In this system, none of the samples showed deliquescence when exposed under water for a long period, indicating no existence of the unstable second phase. Figure 1 shows the X-ray diffraction [abbreviated as XRD] patterns of $(1-\mathrm{x}) \mathrm{NKN}-\mathrm{xBNKT}$ ceramics for $\mathrm{x}=0.01,0.02,0.03,0.04$, and 0.05 . All the compositions were sintered in air at $1100{ }^{\circ} \mathrm{C}$ for $3 \mathrm{~h}$. The main identified phase matches the orthorhombic NKN with space group Amm2 at room temperature, and the results reveal that the orthorhombic structure is preserved. It can be concluded that the NKN-BNKT ceramics have orthorhombic structures in the case $\mathrm{x} \leqq 0.03$. With increasing of BNKT content, however, the structure changes from orthorhombic to tetragonal. A distinct tetragonal splitting can be seen when $\mathrm{x}=0.03$. Therefore, it can be suggested that the specimens of $x=0.03$ correspond to the compositions located in the orthorhombic and tetragonal sides of the MPB, respectively, while the two phases coexist when $\mathrm{x}=0.03$. The measured density and relative density of $(1-\mathrm{x}) \mathrm{NKN}-\mathrm{xBNKT}$ ceramics are shown as a function of $x$ composition in Fig. 2. The measured density and relative density gradually increase with increasing $\mathrm{x}$ and reach a maximum value when $\mathrm{x}$ was added up to 0.03 . Further increasing $\mathrm{x}$, the measured density and relative density will decrease. The measured density of the sintered samples is $90-97 \%$ of the theoretical density. Figure 3 shows the microstructure of the $(1-\mathrm{x}) \mathrm{NKN}-\mathrm{xBNKT}$ ceramics with different BNKT contents. It can be seen in Fig. 6(a) that the 0.99NKN-0.01BNKT ceramics consist of small grains with a loose structure and a high porosity. It can be seen that (1$\mathrm{x}) \mathrm{NKN}-\mathrm{xBNKT}$ ceramics with $\mathrm{x}=0.02 \sim 0.03$ consist of larger grains and denser structure in Fig. $3(\mathrm{~b}) \sim 3(\mathrm{c})$. The grain size of $(1-\mathrm{x}) \mathrm{NKN}-\mathrm{xBNKT}$ decreases with increasing the BNKT contents $(\mathrm{x}=0.04$ to 0.05$)$. Increasing the BNKT contents may cause lattice distortion and a resultant variation in 
composition, which leads to an inhomogeneous microstructure in Fig. 3(d) 3(e). These conditions may increase the porosity and decrease the grain size. With increasing porosity and decreasing the grain size of (1-x)NKN-xBNKT ceramics, the piezoelectric and dielectric properties decrease gradually.

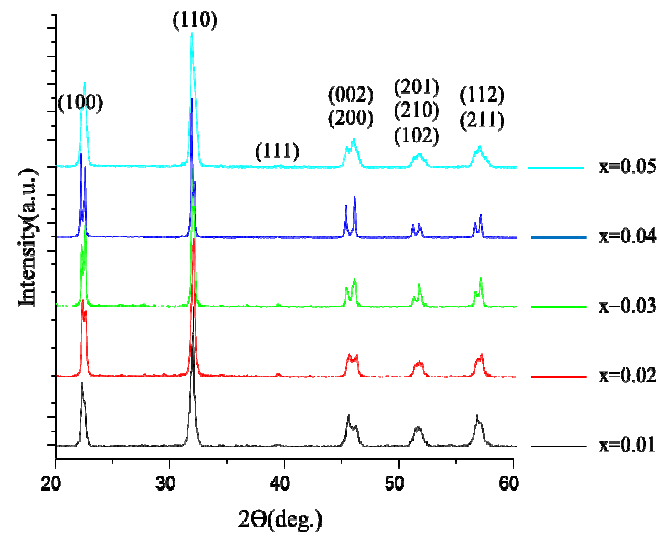

Figure 1. XRD patterns of (1-x)NKN-xBNKT ceramics system with different BNKT contents.

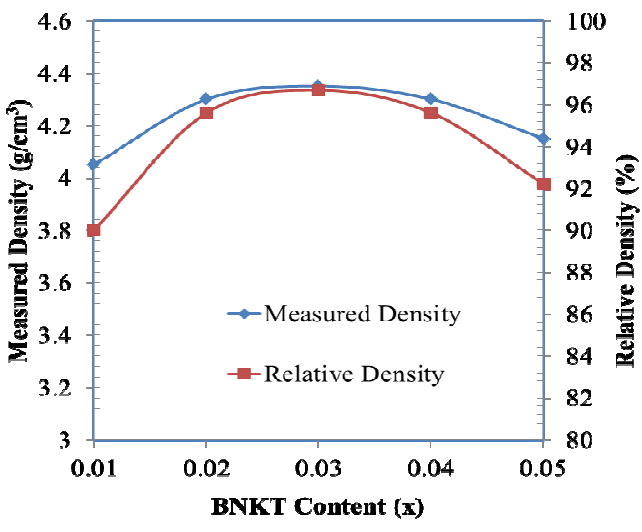

Figure 2. Measured density and relative density BNKT contents.

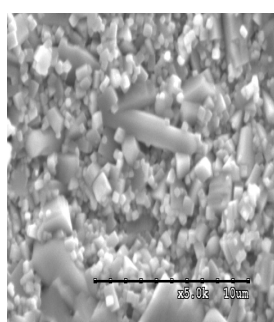

(a) $\mathrm{x}=0.01$

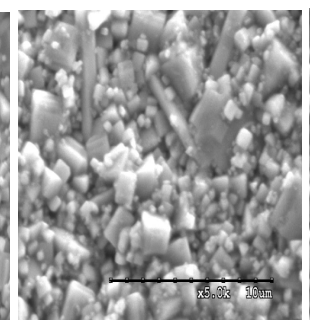

(b) $\mathrm{x}=0.02$

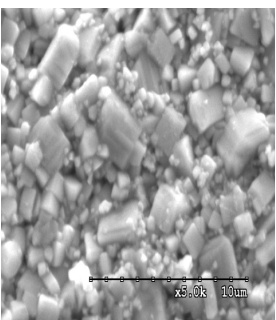

(c) $\mathrm{x}=0.03$

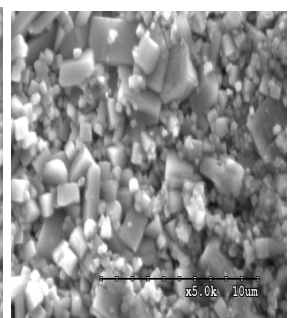

(d) $x=0.04$

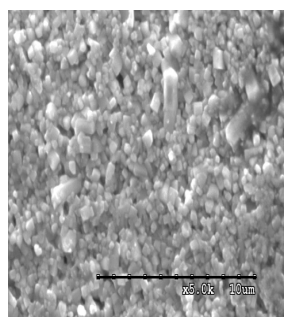

(e) $\mathrm{x}=0.05$

Figure 3. The microstructure of $(16-x) \mathrm{NKN}-\mathrm{xBNKT}$ ceramics with different BNKT contents: (a) $\mathrm{x}=0.01$, (b) $\mathrm{x}=0.02$, (c) $\mathrm{x}=0.03$, (d) $\mathrm{x}=0.04$, and (e) $\mathrm{x}=0.05$. Bar $=10 \mu \mathrm{m}$.

The electromechanical coupling factor is related to different BNKT addition. The planar coupling factor $\left(k_{\mathrm{p}}\right)$ has been used extensively as a measure of the piezoelectric response of PZT type ceramics. It was found that $k_{\mathrm{p}}$ depended on the material parameters such as grain size, porosity, and chemical composition. Piezoelectric activity reaches a maximum value, when ceramic compositions are chosen near those of the morphotropic phase boundary. Usually, the piezoelectric activity is appreciated by the value of the electromechanically coupling factor in radial mode $k_{\mathrm{p}}$. Therefore, $k_{\mathrm{p}}$ is the figure of merit of the piezoelectric activity and the square of that gives the efficiency of the conversion of electrical-mechanical energy. The planar coupling factor $\left(k_{\mathrm{p}}\right)$ and thickness coupling factor $\left(k_{\mathrm{t}}\right)$ of (1$\mathrm{x}) \mathrm{NKN}-\mathrm{xBNKT}$ ceramics are shown as a function of $\mathrm{x}$ composition in Fig. 4. Coupling factor $k_{\mathrm{p}}$ and $k_{\mathrm{t}}$ gradually increase along with increasing $\mathrm{x}$ and reach maximum values when $\mathrm{x}$ was added up to 0.03 . Further increasing $\mathrm{x}, k_{\mathrm{p}}$ and $k_{\mathrm{t}}$ will decrease. In the experiment, the samples possess the optimal $k_{\mathrm{p}}$ and $k_{\mathrm{t}}$ of $29 \%$ of $46 \%$, respectively. Figure 5 shows the dielectric constant and dielectric loss tangent (tan $\delta$ ) of (1-x)NKN-xBNKT ceramics with different BNKT contents. Dielectric constant $\mathrm{K}_{33}^{\mathrm{T}}$ of the samples increases with increasing $\mathrm{x}$ initially, reaches a maximum value $\left(\mathrm{K}^{\mathrm{T}}{ }_{33}=950\right)$ at $\mathrm{x}=0.03$. Going on increasing $\mathrm{x}, \mathrm{K}^{\mathrm{T}}{ }_{33}$ shows a obvious decrease. The variation trend of the dielectric loss tangent ( $\tan$ $\delta$ ) with BNKT contents is inverse to that of the measured density. The minimum value of the dielectric loss tangent $(\tan \delta=0.04)$ is found at the phase boundary $(\mathrm{x}=0.03)$. 


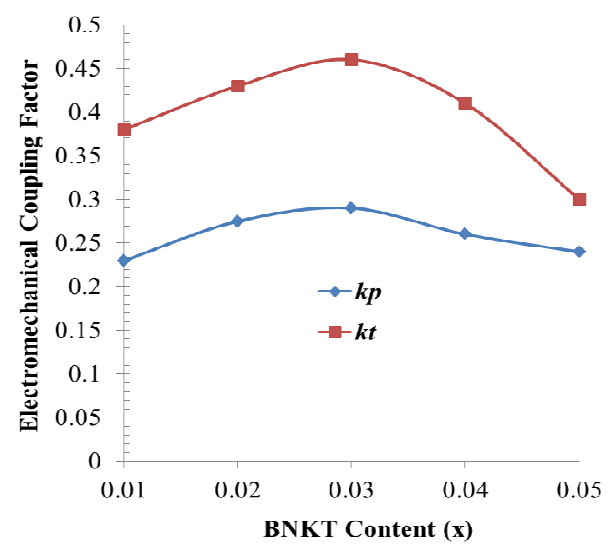

Figure 4. The electromechanical quality factor $(\mathrm{kp}$ and $\mathrm{kt})$ of (1-x) NKN - xBNKT ceramics as a function of BNKT contents.

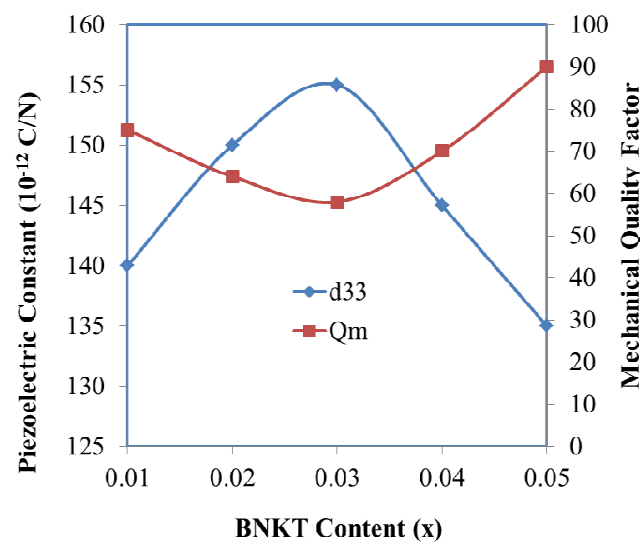

Figure 6. The piezoelectric constant and mechanical quality factor of (1-x)NKN-xBNKT ceramics as a function of BNKT contents.

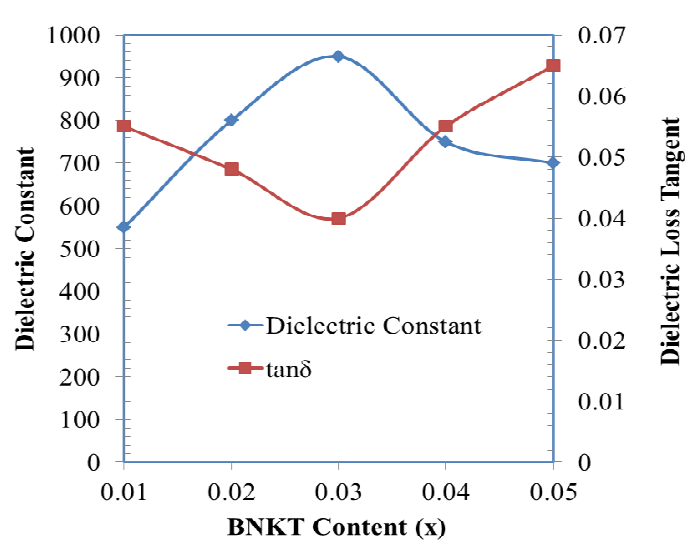

Figure 5. The dielectric constant and dielectric loss tangent $(\tan \delta)$ of $(1-\mathrm{x}) \mathrm{NKN}-\mathrm{xBNKT}$ ceramics as a function of BNKT contents.

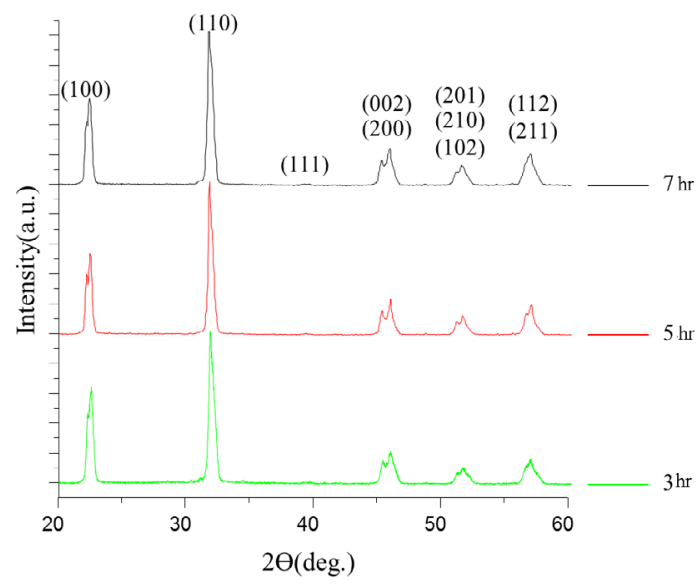

Figure 7. XRD patterns of $0.97 \mathrm{NKN}-0.03 \mathrm{BNKT}$ ceramics sintered at $1100^{\circ} \mathrm{C}$ for different time (a) 3 h(b) $5 \mathrm{~h}$ (c) $7 \mathrm{~h}$.

Figure 6 shows the piezoelectric constant $\left(\mathrm{d}_{33}\right)$ and the mechanical quality factor $\left(Q_{\mathrm{m}}\right)$ of $(1$ $\mathrm{x}) \mathrm{NKN}-\mathrm{xBNKT}$ ceramics with different BNKT contents. The piezoelectric constant $\left(\mathrm{d}_{33}\right)$ gradually increase along with increasing $x$ and reach a maximum value $\left(\mathrm{d}_{33}=155 \mathrm{pC} / \mathrm{N}\right)$ when $\mathrm{x}$ was added up to 0.03 . Further increasing $x$, the $d_{33}$ will decrease. The mechanical quality factor increases with an increase of BNKT contents. The variation trend of the mechanical quality factor $\left(Q_{\mathrm{m}}\right)$ with BNKT contents is inverse to that of the planar coupling factor $\left(k_{\mathrm{p}}\right)$. The content-depended effect of BNKT on the properties of NKN-BNKT ceramics can be attributed to two factors : the chemical modification and the crystalline structure influence of the material. When BNKT-content doped is relatively low, chemical modification caused by dissolution of BNKT into the NKN lattice plays a major role on the properties of NKN-BNKT ceramics. It is supposed that $\mathrm{NKN}$ is $\mathrm{ABO}_{3}$ perovskite structure materials. When BNKT as an additive was added into ceramics, it is the most likely that the $\mathrm{Bi}^{3+}(1.4 \AA$ ionic radius) could substitute for $\mathrm{K}^{+}(1.64 \AA)$ and $\mathrm{Na}^{+}(1.39 \AA)$ in the A site, while $\mathrm{Ti}^{4+}(0.61 \AA)$ could substitute for $\mathrm{Nb}^{5+}(0.64 \AA)$ in the $\mathrm{B}$ sites of $\mathrm{ABO}_{3}$ perovskite structure. The substitute of one $\mathrm{Bi}^{3+}$ ion could creates two vacancy at the A site, which can relax the strain caused by reorinentation of ferroelectric domains. Therefore, domains in NKN-BNKT ceramics can be sufficiently reoriented 
during the polarization process. On the other hand, due to the difference of ionic radius between $\mathrm{Ti}^{4+}$ and $\mathrm{Nb}^{5+}$ ions, this substitution will result in an aberrance of crystalline structure, which benefits the reorientation of domains. That may be the explanation for the increase of piezoelectric properties. However, further increasing BNKT contents ( $>3$ mole \% BNKT), chemical modification play a major role on the properties of NKN-BNKT ceramics again. Increasing the BNKT contents, due to the difference of ionic radius among $\mathrm{K}^{+}, \mathrm{Na}^{+}$and $\mathrm{Bi}^{+3}$ ions in the $\mathrm{A}$ site, may cause lattice distortion and a resultant variation in composition, which leads to an inhomogeneous microstructure. These conditions may increase the porosity and decrease the grain size, as shown in Fig. 6(d) 6(e). With increasing porosity and decreasing the grain size of $(1-\mathrm{x}) \mathrm{NKN}-\mathrm{xBNKT}$ ceramics, the piezoelectric and dielectric properties decrease gradually. Figure 7 shows the $\mathrm{XRD}$ patterns of $0.97\left(\mathrm{Na}_{0.5} \mathrm{~K}_{0.5}\right) \mathrm{NbO}_{3^{-}}$ $0.03 \mathrm{Bi}\left(\mathrm{Na}_{0.83} \mathrm{~K}_{0.17}\right) \mathrm{TiO}_{3}$ [abbreviated $0.97 \mathrm{NKN}-0.03 \mathrm{BNKT}$ ] with different sintering time $(3,5$ and $7 \mathrm{~h})$ at $1100{ }^{\circ} \mathrm{C}$. The orthorhombic and tetragonal phase of $0.97 \mathrm{NKN}-0.03 \mathrm{BNKT}$ ceramics at room temperature is characterized on the XRD patterns in the $2 \theta$ ranges of $44 \sim 48^{\circ}$. The XRD analysis of sintered samples shows that $0.97 \mathrm{NKN}-0.03 \mathrm{BNKT}$ is sure of a perovskite structure and forms a solid solution. The BNKT appears to have diffused into the NKN lattice to form a solid solution, in which $\mathrm{Ba}^{+2}$ ion occupies $\left(\mathrm{Na}^{+}, \mathrm{K}^{+}\right)$lattice and $\mathrm{Ti}^{+4}$ ion enters $\mathrm{Nb}^{+5}$ sites of $\mathrm{NKN}$. As increasing the sintering time, the patterns of the $0.97 \mathrm{NKN}-0.03 \mathrm{BNKT}$ ceramics do not change in evidence.

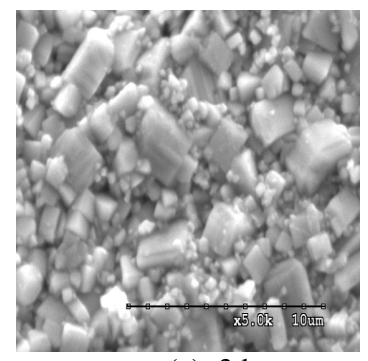

(a) $3 \mathrm{~h}$.

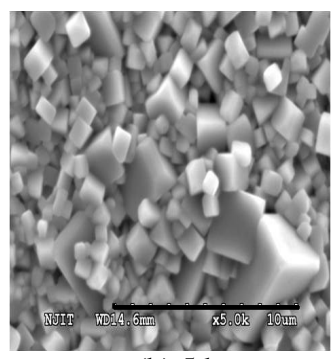

(b) $5 \mathrm{~h}$.

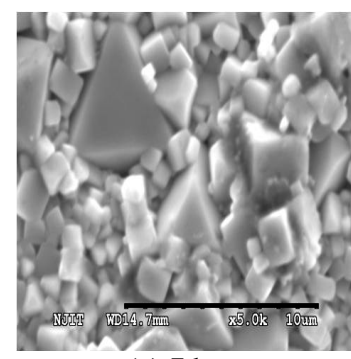

(c) $7 \mathrm{~h}$.

Figure 8. SEM images of $0.97 \mathrm{NKN}-0.03 \mathrm{BNKT}$ ceramics sintered at $1100^{\circ} \mathrm{C}$ for different time (a) $3 \mathrm{~h}$. (b) $5 \mathrm{~h}$ (c) $7 \mathrm{~h} . \mathrm{Bar}=10 \mu \mathrm{m}$

Figure 8 shows the microstructure of $0.97 \mathrm{NKN}-0.03 \mathrm{BNKT}$ ceramics sintered at $1100{ }^{\circ} \mathrm{C}$ for different time (a) $3 \mathrm{~h}$ (b) $5 \mathrm{~h}$ and (c) $7 \mathrm{~h}$. It can be seen that the $0.97 \mathrm{NKN}-0.03 \mathrm{BNKT}$ ceramics consist of very small grains, with a relatively loose structure, and a high porosity in Fig. 8(a). However, the $0.97 \mathrm{NKN}-0.03 \mathrm{BNKT}$ ceramic at the sintering time $0 \mathrm{~h}$ are denser, with low porosity, and exhibit a larger and grain size of $\sim 2.5 \mu \mathrm{m}$ in Fig. 8(b). In Fig. 8(c), the irregular shape is found. According to "COBLE" models, "discontinuous" grain growth is the nomenclature selected here for the occurrence various called discontinuous or exaggerated, or second recrystallization. This may increase the porosity, attributed to a longer sintering time. Figure 9 to 12 show the physical and electrical properties of $0.97 \mathrm{NKN}-0.03 \mathrm{BNKT}$ sintered at $1100{ }^{\circ} \mathrm{C}$ for different time. The measured density and relative density of $0.97 \mathrm{NKN}-0.03 \mathrm{BNKT}$ sintered $1100{ }^{\circ} \mathrm{C}$ at different time were shown in Fig. 9. The measured density and relative density increase with increasing the sintering time until it reaches $5 \mathrm{~h}$, then decreases above $5 \mathrm{~h}$. The real density and relative density of the sintered samples is $95-98 \%$ of the theoretical density. The electromechanical coupling factor $\left(k_{\mathrm{p}}\right.$ and $\left.k_{t}\right)$ of $0.97 \mathrm{NKN}-0.03 \mathrm{BNKT}$ sintered $1100{ }^{\circ} \mathrm{C}$ at different time were shown in Fig. 10. Coupling factor $k_{\mathrm{p}}$ and $k_{\mathrm{t}}$ gradually increase along with the sintering time and reach maximum values $\left(k_{\mathrm{p}}=0.32, k_{l}=0.56\right)$ when $\mathrm{x}$ was added up to $5 \mathrm{~h}$. Further increasing the sintering time, $k_{\mathrm{p}}$ and $k_{\mathrm{t}}$ will decrease. The dielectric constant and dielectric loss tangent $(\tan \delta)$ of $0.97 \mathrm{NKN}-0.03 \mathrm{BNKT}$ sintered $1100{ }^{\circ} \mathrm{C}$ at different time were shown in Fig 11. The dielectric constant increases with increasing the sintering time until it reaches $5 \mathrm{~h}$, then decreases above $5 \mathrm{~h}$. The variation trend of the dielectric loss tangent $(\tan \delta)$ with BNKT contents is inverse to that of the measured density. The mechanical quality factor $\left(\mathrm{Q}_{\mathrm{m}}\right)$ and piezoelectric constant $\left(\mathrm{d}_{33}\right)$ of $0.97 \mathrm{NKN}-0.03 \mathrm{BNKT}$ sintered $1100{ }^{\circ} \mathrm{C}$ at different time were shown in Fig.12. The mechanical quality factor $\left(\mathrm{Q}_{\mathrm{m}}\right)$ and piezoelectric constant $\left(\mathrm{d}_{33}\right)$ reaches maximum values $\left(\mathrm{Q}_{\mathrm{m}}=50, \mathrm{~d}_{33}=190 \mathrm{pC} / \mathrm{N}\right)$ at the sintering time of $5 \mathrm{~h}$. 


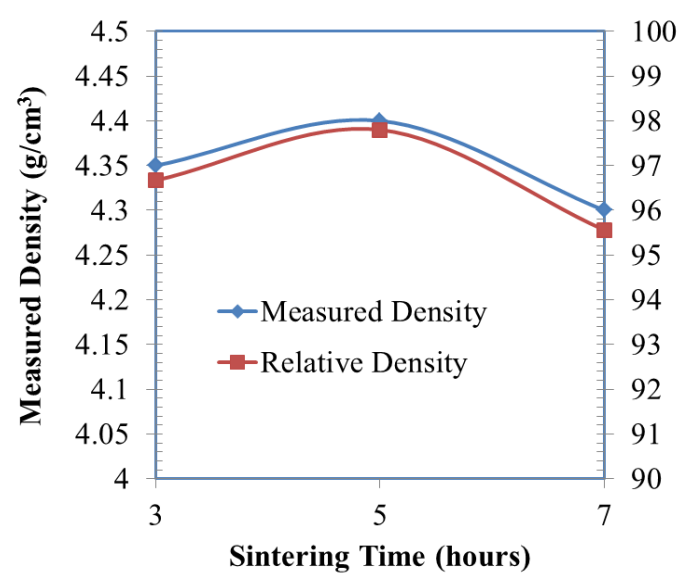

Figure 9. Measured density and relative density of $0.97 \mathrm{NKN}-0.03 \mathrm{BNKT}$ ceramics as a function of sintering time at $1100^{\circ} \mathrm{C}$.

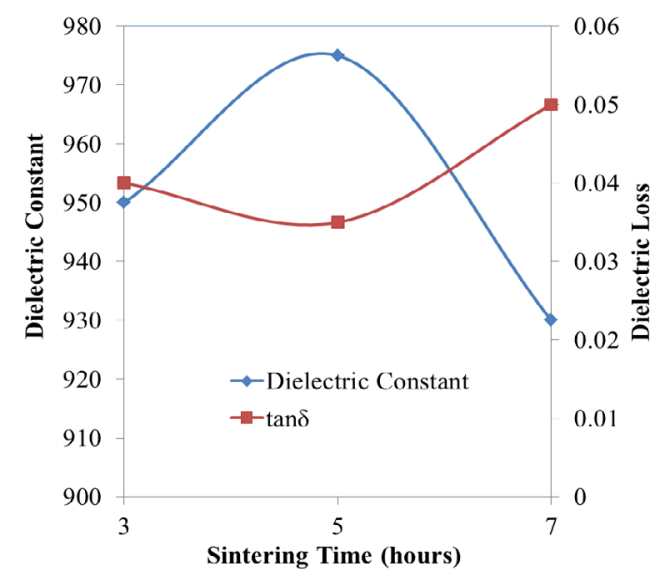

Figure 11. The dielectric constant and dielectric loss tangent $(\tan \delta)$ of $0.97 \mathrm{NKN}-0.03 \mathrm{BNKT}$ ceramics as a function of sintering time at $1100{ }^{\circ} \mathrm{C}$.

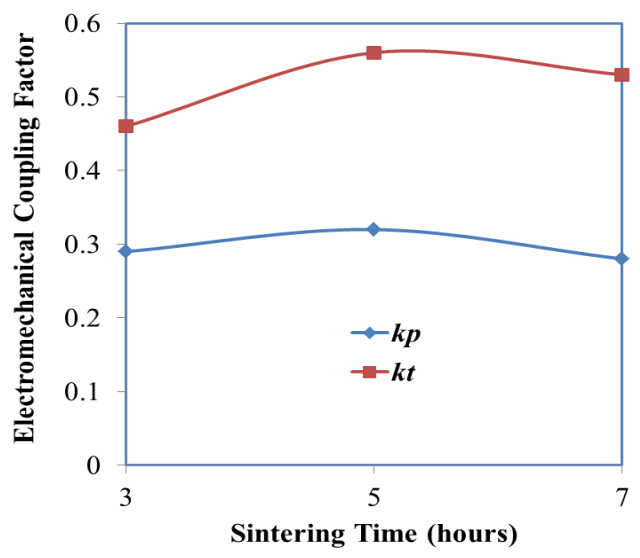

Figure 10. The electromechanical quality factor $\left(k_{\mathrm{p}}\right.$ and $k_{\mathrm{t}}$ ) of $0.97 \mathrm{NKN}-0.03 \mathrm{BNKT}$ ceramics as a function of sintering time at $1100{ }^{\circ} \mathrm{C}$.

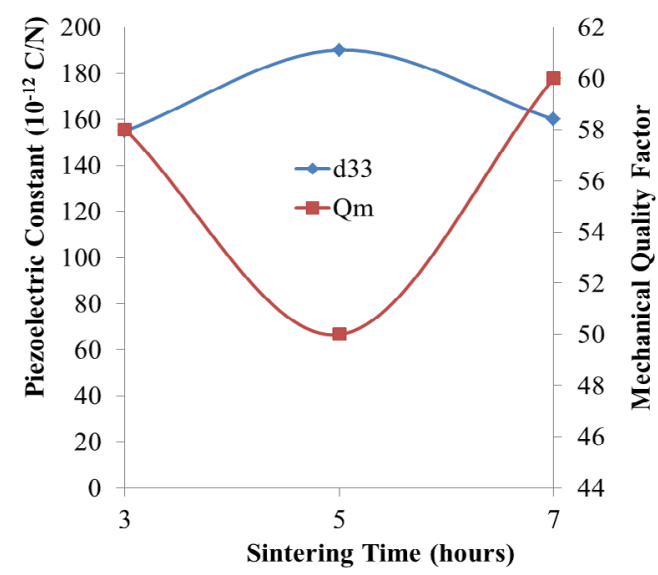

Figure 12. The piezoelectric constant $\left(\mathrm{d}_{33}\right)$ and $\mathrm{Q}_{\mathrm{m}}$ of $0.97 \mathrm{NKN}-0.03 \mathrm{BNKT}$ ceramics as a function of sintering time at $1100{ }^{\circ} \mathrm{C}$.

\section{Summary}

The (1-x)NKN-xBNKT $(x=0.01,0.02,0.03,0.04$ and 0.05$)$ binary system had been prepared by a conventional ceramic sintering technique. From the XRD patterns, a MPB between orthorhombic and tetragonal phase appears at $\mathrm{x}=0.03$. For $0.97 \mathrm{NKN}-0.03 \mathrm{BNKT}$ ceramics, the electromechanical coupling coefficients of the planar mode $k_{\mathrm{p}}$, the thickness mode $k_{\mathrm{t}}$ and the piezoelectric constant $\mathrm{d}_{33}$ reach $0.29,0.46$ and $155 \mathrm{pC} / \mathrm{N}$, respectively, at the sintering of $1100{ }^{\circ} \mathrm{C}$ for $3 \mathrm{~h}$.

The effect of sintering time on the properties of $0.97 \mathrm{NKN}-0.03 \mathrm{BNKT}$ ceramics was discussed. For $0.97 \mathrm{NKN}-0.03 \mathrm{BNKT}$ ceramics, the planar electromechanical coupling coefficient $k_{p}$, the thickness electromechanical coupling coefficient $k_{t}$ and the piezoelectric constant $\mathrm{d}_{33}$ reach $0.32,0.56$ and 190 $\mathrm{pC} / \mathrm{N}$, respectively at the sintering of $1100{ }^{\circ} \mathrm{C}$ for $5 \mathrm{~h}$. Prolonging the sintering time to the $0.97 \mathrm{NKN}-$ $0.03 \mathrm{BNKT}$ system is a helpful method on ceramic processing to improve densification and properties. Our results show that $0.97 \mathrm{NKN}-0.03 \mathrm{BNKT}$ solid solution ceramics are promising lead-free ceramics for a wide range of electromechanical transducer applications. 


\section{References}

1. G. Shirane, R. Newnham, and R. Pepinsky, Phys. Rev., 96, 581 (1954)

2. M. D. Maeder, D. Damjanovic, and N. Setter, J. Electroceram., 13, 385 (2004)

3. V. Lingwal, B. S. Semwal, and N. S. Panwar, Bull. Mater. Sci., 26, 619 (2003)

4. H. Birol, D. Damjanovic, and N. Setter, J. Eur. Ceram. Soc., 26, 861 (2006)

5. T. Takenaka, H. Nagata, and Y. Hiruma, Jpn. J. Appl. Phys., 47, 3787 (2008)

6. S. Y. Chu, W. Water, Y. D. Juang, J. T. Liaw, and S. B. Dai, Ferroelectrics, 297, 11 (2003)

7. M. Matsubara,T.Yamaguchi, K. Kikuta, and S. Hirano, Jpn. J. Appl. Phys., 44, 6136 (2005) 